This is a self-archived version of an original article. This version may differ from the original in pagination and typographic details.

Author(s): Puttreddy, Rakesh; von Essen, Carolina; Rissanen, Kari

Title: Halogen Bonds in Square Planar 2,5-Dihalopyridine-Copper(II) Bromide Complexes

Year: 2018

Version: Accepted version (Final draft)

Copyright: (c) 2018 Wiley-VCH Verlag GmbH \& Co.

Rights: In Copyright

Rights url: http://rightsstatements.org/page//nC/1.0/?language=en

Please cite the original version:

Puttreddy, R., von Essen, C., \& Rissanen, K. (2018). Halogen Bonds in Square Planar 2,5Dihalopyridine-Copper(II) Bromide Complexes. European Journal of Inorganic Chemistry, 2018(20-21), 2393-2398. https://doi.org/10.1002/ejic.201800144 


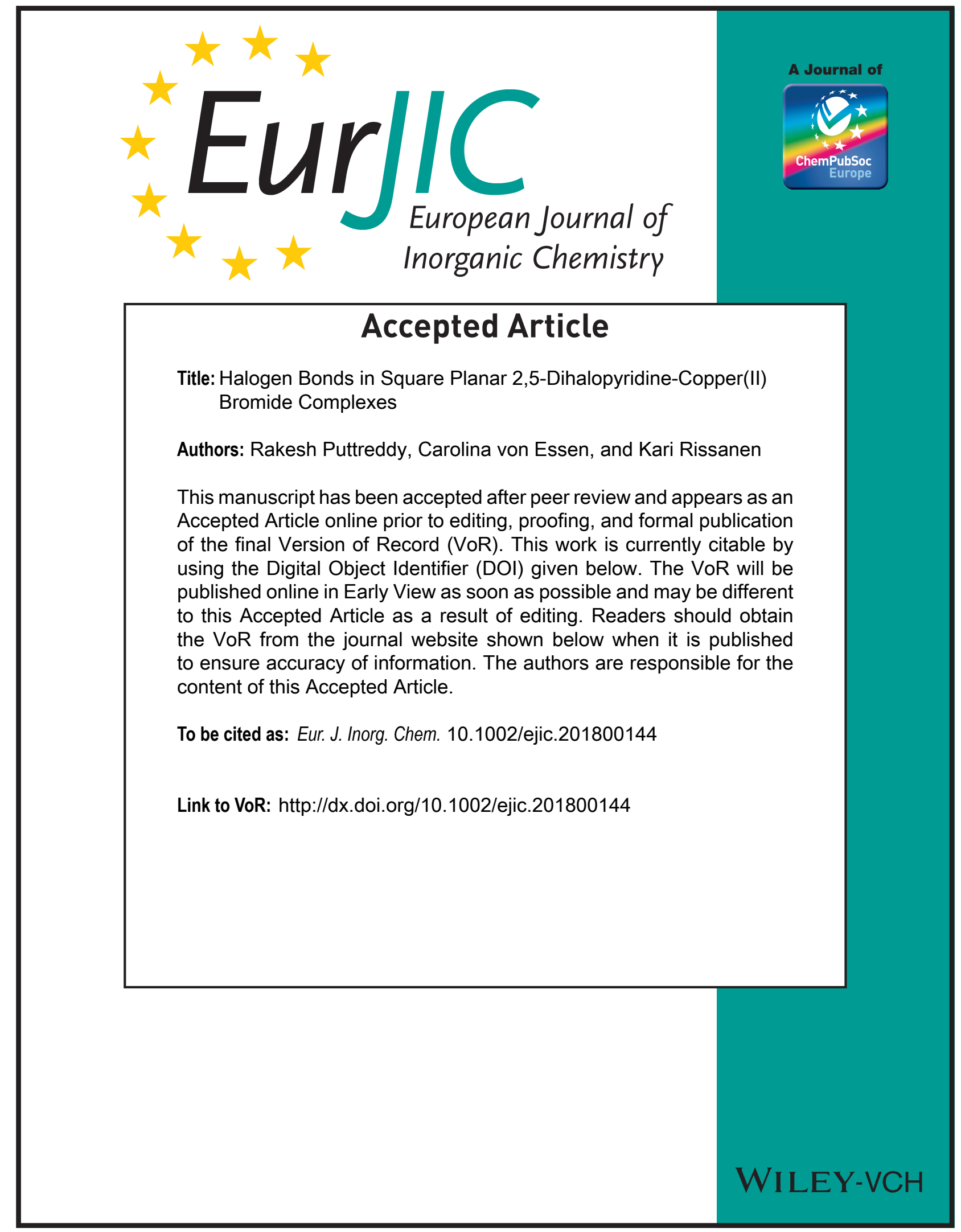


WILEY-VCH

\title{
Halogen Bonds in Square Planar 2,5-Dihalopyridine-Copper(II) Bromide Complexes
}

\author{
Rakesh Puttreddy, ${ }^{[a]}$ Carolina von Essen, ${ }^{[a]}$ and Kari Rissanen*[a] \\ Dedication ((optional))
}

\begin{abstract}
Halogen bonding in self-complementary 1:2 metal-ligand complexes obtained from copper(II) bromide $\left(\mathrm{CuBr}_{2}\right)$ and seven 2,5dihalopyridines are analyzed using single crystal $\mathrm{X}$-ray diffraction. All presented discrete complexes form 1-D polymeric chains connected with $\mathrm{C}-\mathrm{X} \cdots \mathrm{Br}-\mathrm{Cu}$ halogen bonds (XB). In (2-chloro-5-Xpyridine $)_{2} \cdot \mathrm{CuBr}_{2}(\mathrm{X}=\mathrm{Cl}, \mathrm{Br}$ and $\mathrm{I})$, only the $\mathrm{C} 5$-halogen, and in (2bromo-5-X-pyridine $)_{2} \cdot \mathrm{CuBr}_{2}(\mathrm{X}=\mathrm{Cl}, \mathrm{Br}$ and I) both, $\mathrm{C} 2$ - and $\mathrm{C} 5$ halogens, form $\mathrm{C}-\mathrm{X} \cdots \mathrm{Br}-\mathrm{Cu}$ halogen bonds with the $\mathrm{X}$ acting as the $\mathrm{XB}$ donor and copper-coordinated bromide as the $\mathrm{XB}$ acceptor. The electron withdrawing $\mathrm{C} 2$-chloride in 2-chloro-5-X-pyridine- $\mathrm{CuBr}_{2}$ complexes has only a minor effect on the $\mathrm{C} 5-\mathrm{X} 5 \cdots \mathrm{Br}-\mathrm{Cu} \mathrm{XBs}$, and the $\mathrm{X} 5 \cdots \mathrm{Br}$ distances follow expected order, $15<\mathrm{Br} 5<\mathrm{Cl} 5$ in the $\mathrm{RXB}$ values of $0.91,0.94$ and 0.99 , respectively. In 2-bromo-5-X-pyridine$\mathrm{CuBr}_{2}$ complexes, due to the polarization of both halogens, the $\mathrm{C} 2$ $\mathrm{X} 2 \cdots \mathrm{Br}-\mathrm{Cu}$ and $\mathrm{C} 5-\mathrm{X} 5 \cdots \mathrm{Br}-\mathrm{Cu}$ the $\mathrm{R}_{\mathrm{XB}}$ values are very similar $[0.92$ - 0.99] due to competition of C2- and C5-halogens for XB formation. In addition to the classical halogen bonds the square planar $\mathrm{Cu}(\mathrm{II})$ complexes exhibit $\mathrm{C} 2-\mathrm{X} 2 \cdots \mathrm{Cu}(\mathrm{X}=\mathrm{Cl}$ and $\mathrm{Br})$ contacts perpendicular to the $\mathrm{Br}-\mathrm{Cu}-\mathrm{Br}$ plane with shorter $\mathrm{C} 2-\mathrm{Br} 2 \cdots \mathrm{Cu}$ than $\mathrm{C} 2-\mathrm{Cl} 2 \cdots \mathrm{Cu}$ contacts. These interactions induce a pseudo-octahedral geometry for $\mathrm{Cu}(\mathrm{II})$ ions. Notably, $\mathrm{C} 2-\mathrm{X} 2 \cdots \mathrm{Br}-\mathrm{Cu}$ halogen bonds and the additional $\mathrm{C} 2-\mathrm{X} 2 \cdots \mathrm{Cu}$ contacts are slightly enhanced by the $\mathrm{C} 5$ halogen electronegativity.
\end{abstract}

\section{Introduction}

The importance of hydrogen bonds ${ }^{[1]}(\mathrm{HB})$ in organic, organometallic and inorganic compounds has led to significant interest to other non-covalent interactions, most recently to the utilization of halogen bonding. The halogen bonds (XB), are predominantly studied in organic molecules and in the solid-state, as strong, specific and highly directional non-covalent interactions equivalent to HBs resulting in a rapidly developing area within supramolecular chemistry. ${ }^{[2]}$ Over the past decade, $C-X \cdots A-C$ [C = carbon, $\mathrm{X}=$ halogen as $\mathrm{XB}$ donor, $\mathrm{A}=\mathrm{XB}$ acceptor, often halide anion], halogen bonding interactions have been of growing interest as valuable crystal engineering tool. ${ }^{[3]}$ The halogen bond has recently been defined ${ }^{[4]}$ by IUPAC and has recently been

[a] Rakesh Puttreddy, Carolina von Essen and Kari Rissanen University of Jyvaskyla, Department of Chemistry, P.O. Box. 35, 40014 Jyväskylä, Finland

E-mail: rakesh.r.puttreddy@jyu.fi and kari.t.rissanen@jyu.fi https://www.jyu.fi/science/en/chemistry/research/structural-andsynthetic-chemistry/the-supramolecular-chemistry

Supporting information for this article is given via a link at the end of the document. extensively studied, ${ }^{[2-3]}$ also for complex halide anions ${ }^{[5]}$ using solid-state X-ray crystallography and computational methods. ${ }^{[2-6]}$ In transition metal complexes, the importance and the role of two descriptors are well studied, viz., (a) primary coordination sphere or metal-ligand interactions, and (b) secondary coordination sphere or non-covalent interactions. ${ }^{[7]}$ Structure and reactivity of metal complexes depend on metal-ligand interactions, while most chemical and physical properties are influenced by non-covalent interactions, e.g. HB and XB. In the solid-state X-ray crystal structures, the functional groups attached to the ligands in the coordination complexes gives rise to rich chemical environments allowing for variety of intra- and intermolecular non-covalent interactions from the substituents. To investigate $\mathrm{XBs}$ in metal complexes, halopyridines coordinated to metal ions makes it possible to study both $\mathrm{C}-\mathrm{X} \cdots \mathrm{A}-\mathrm{C}$ and $\mathrm{C}-\mathrm{X} \cdots \mathrm{A}-\mathrm{M}[\mathrm{X}=$ halogen substituent, $M=$ metal ion, $A=X B$ acceptor] interactions. $A$ few research groups, mainly, Brammer et al., ${ }^{[8]}$ have crystallographically studied complexes of the type $M(L X)_{2} A_{2}[L X=$ 2-, 3- and 4-halopyridines, $M=$ metal and $A=$ metal bound halides], where $A$ acts as $X B$ acceptor and $X$ as $X B$ donor. Furthermore, Brammer et al. explored the cooperative and competitive nature of $\mathrm{HBs}$ and $\mathrm{XBs}$ of $[\mathrm{LH}]^{+}$species as acceptors to tetrahedral $\mathrm{MA}_{4}$ anions. ${ }^{[9]}$ To complement this, we have previously studied neutral pincer type viz., $\{2,6-b i s[(d i-t-$ butylphosphino)-methyl]phenyl\}P $\mathrm{PY}(\mathrm{Y}=\mathrm{Cl}, \mathrm{Br}$ and I) and (terpyridine) $\mathrm{Me}_{3} \mathrm{Ptl}$ complexes where the metal bound halogen acts as the XB acceptor. ${ }^{[10]}$

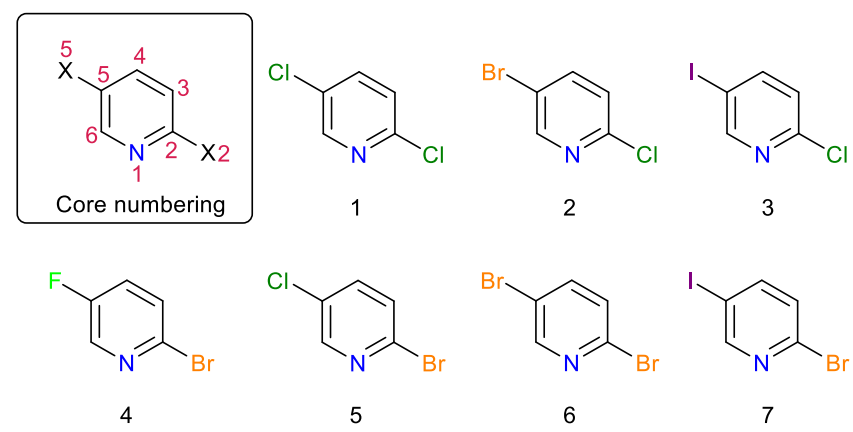

Figure 1. Representation of 2,5-dihalopyridine core numbering, and chemical structures of 2,5-dichloropyridine (1), 5-bromo-2-chloropyridine (2), 2-chloro-5iodopyridine (3), 2-bromo-5-fluoropyridine (4), 2-bromo-5-chloropyridine (5), 2,5-dibromopyridine (6) and 2-bromo-5-iodopyridine (7).

In the present study, we analyze the halogen bonds in coordination complexes formed from 2,5-dihalopyridines and copper(II) bromide $\left(\mathrm{CuBr}_{2}\right)$. We utilize a series of seven 2,5dihalopyridines, three based on 2-chloropyridine (1-3) and four based on 2-bromopyridine (5-7), with a different halogen substitiuent at the 5-position of the pyridine ring [X5, Fig. 1]. We anticipated that, upon complexation with $\mathrm{CuBr}_{2}$, the $\mathrm{X} 5$ 
substituent will be electronically influenced by the $\mathrm{X} 2$ substituent as it resides close to positive $\mathrm{Cu}(\mathrm{II})$ coordination sphere. The formally negatively-charged bromide atoms bound to the $\mathrm{Cu}$ (II) ion are nucleophilic enough to act as the XB acceptors. However, considering different coordination geometries of $\mathrm{Cu}(\mathrm{II})$ and the orientation of ligands influenced by crystal packing interactions, this study further aims to examine: (a) whether either $\mathrm{X} 2$ or $\mathrm{X} 5$ or both of them are able to form $\mathrm{C}-\mathrm{X} \cdots \mathrm{Br}-\mathrm{Cu}$ halogen bonds in the solid-state. The crystallographic studies are supplemented by qualitative analysis of the electrostatic potential surfaces of the complexes, viz. by visualizing the modulation of the $\sigma$-hole at the $\mathrm{X} 2$ or X5 substituent or vice versa. In the following discussion, 2 chloro-, 2-bromo-, 3-chloro- and 3-bromopyridines from the literature $^{[11]}$ are abbreviated as $2 \mathrm{CIPy}, 2 \mathrm{BrPy}, 3 \mathrm{CIPy}$ and $3 \mathrm{BrPy}$.

\section{Results and Discussion}

The complexes were synthesized by mixing a 2:1 molar ratio of 2,5-dihalopyridine and $\mathrm{CuBr}_{2}$ in acetonitrile at room temperature. If necessary, the reaction mixtures were sonicated to dissolve all the components. Slow evaporation of the resulting solution provides single crystals suitable for X-ray crystallography (See Experimental Section for more details). Attempts to obtain crystals with 2-chloro-5-fluoropyridine were unsuccessful. In all complexes, the $\mathrm{Cu}(\mathrm{II})$ ion binds to two 2,5-dihalopyridine ligands and has centrosymmetric $\mathrm{N}_{2} \mathrm{Br}_{2}$ coordination sphere. In complexes $(1)_{2} \cdot \mathrm{CuBr}_{2}$ and $(2)_{2} \cdot \mathrm{CuBr}_{2}, \mathrm{Cu}(\mathrm{II})$ is square planar, while $(3)_{2} \cdot \mathrm{CuBr}_{2}$ has see-saw geometry with an $\tau_{4}$ value of $0.47 .^{[12]}$ In contrast to the reported square planar structure, (2$\mathrm{CIPy})_{2} \cdot \mathrm{CuBr}_{2}\left(\mathrm{CCDC}\right.$ code PAMLEW), ${ }^{[11 \mathrm{a}]}$ the C2-chlorides in $(1)_{2} \cdot \mathrm{CuBr}_{2}$ and $(2)_{2} \cdot \mathrm{CuBr}_{2}$ are in anti-arrangement. However, the anti-arrangement of $\mathrm{X} 5$ substituent in (1) ${ }_{2} \cdot \mathrm{CuBr}_{2}$ and $(2)_{2} \cdot \mathrm{CuBr}_{2}$ is similar to $\left(3-\mathrm{CIPy}_{2} \cdot \mathrm{CuBr}_{2}(\mathrm{CCDC} \text { code PAMKUL })^{[11 a]}\right.$ and (3$\mathrm{BrPy})_{2} \cdot \mathrm{CuBr}_{2}$ (CCDC code YENXUL). ${ }^{[11 \mathrm{~b}]}$ The small energy difference between syn- and anti-arrangements of the $\mathrm{Cl} 2$ substituents are reported, ${ }^{[11 \mathrm{a}]}$ the $\mathrm{C} 2-\mathrm{Cl} 2 \cdots \mathrm{Cu}$ contacts, particularly in anti-positions play a crucial role to stabilize square planar rather than distorted four coordinate $\mathrm{Cu}(\mathrm{II})$ geometries. The trans- $\mathrm{C} 2-\mathrm{Cl} 2 \cdots \mathrm{Cu}$ contacts of $3.0 \AA$ around $\mathrm{Cu}(\mathrm{II})$ ion in $(1)_{2} \cdot \mathrm{CuBr}_{2}$ and $(2)_{2} \cdot \mathrm{CuBr}_{2}$ are remarkably short, ca. $3.04 \AA$, while the distance of ca. $3.12 \AA$ around see-saw geometry $\mathrm{Cu}(\mathrm{II})$ ion in (3) $)_{2} \cdot \mathrm{CuBr}_{2}$ is similar to reported $(2 \mathrm{CIPy})_{2} \cdot \mathrm{CuBr}_{2}[\mathrm{Fig} .2 \mathrm{~d}] .^{[11 \mathrm{a}]}$
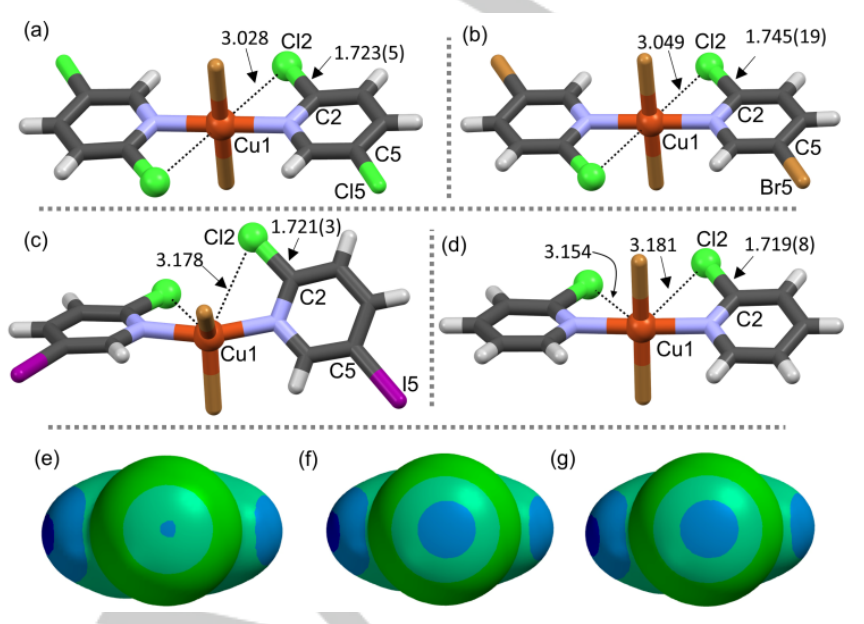

Figure 2. X-ray crystal structure of (a) (1) $)_{2} \cdot \mathrm{CuBr}_{2}$, (b) (2) $)_{2} \cdot \mathrm{CuBr}_{2}$, (c) and $(3)_{2} \cdot \mathrm{CuBr}_{2}$ compared with the previously reported ${ }^{[11 \mathrm{a}]}$ structure of (d) $(2 \mathrm{CIPy})_{2} \cdot \mathrm{CuBr}_{2}$. The electrostatic potential surfaces of $\mathrm{X} 5$ in free ligands (e) for $1(\mathrm{Cl})$, (f) for $2(\mathrm{Br})$ and $(\mathrm{g})$ for $3(\mathrm{I})$.

Complexes $(1)_{2} \cdot \mathrm{CuBr}_{2}$ and $(2)_{2} \cdot \mathrm{CuBr}_{2}$ are isomorphous and isostructural, and $(3)_{2} \cdot \mathrm{CuBr}_{2}$ is remarkably different in both crystallographic cell parameters as well as from structural perspective. The discrete metal complexes are extended to 1-D polymers via $\mathrm{C} 5-\mathrm{X} 5 \cdots \mathrm{Br}-\mathrm{Cu}(\mathrm{X}=\mathrm{Cl}, \mathrm{Br}$ and $\mathrm{I})$ halogen bonds, as shown in Fig. 3 and Table 1. The C2-chlorides in $(1)_{2} \cdot \mathrm{CuBr}_{2}$ and $(2)_{2} \cdot \mathrm{CuBr}_{2}$ are not showing halogen bonding. The $\mathrm{C} 5-\mathrm{Cl} 5 \cdots \mathrm{Br}-$ $\mathrm{Cu}$ and $\mathrm{C} 5-\mathrm{Br} 5 \cdots \mathrm{Br}-\mathrm{Cu}$ halogen bonds in (1) $)_{2} \cdot \mathrm{CuBr}_{2}\left[\mathrm{R}_{\mathrm{XB}}=0.99\right]$ and $(2)_{2} \cdot \mathrm{CuBr}_{2}\left[\mathrm{R}_{X \mathrm{~B}}=0.94\right]$ are stronger when compared to $\mathrm{C}_{3}-$ $\mathrm{X} 3 \cdots \mathrm{Br}-\mathrm{Cu}$ distances observed in $(3-\mathrm{ClPy})_{2} \cdot \mathrm{CuBr}_{2}[\mathrm{R} \times \mathrm{B}=$ $1.02]^{[11 \mathrm{a}]}$ and $(3-\mathrm{BrPy})_{2} \cdot \mathrm{CuBr}_{2}\left[\mathrm{RxB}_{\mathrm{X}}=0.98\right]^{[11 \mathrm{~b}]}$, respectively. This suggests that the electron withdrawing $\mathrm{Cl} 2$-substituent para to $\mathrm{X} 5$ increase the electrophilic character of $X 5$ resulting in shorter $C_{5}$ $\mathrm{X} 5 \cdots \mathrm{Br}-\mathrm{Cu}$ contacts. Despite the $\mathrm{Cl} 2$ being $\mathrm{XB}$ passive in (1) $)_{2} \cdot \mathrm{CuBr}_{2}$ and $(2)_{2} \cdot \mathrm{CuBr}_{2}$, the 1-D chains are connected via weak $\mathrm{C} 2-\mathrm{Cl} 2 \cdots \mathrm{H}-\mathrm{C} 3 \mathrm{HB}$ interactions to form a 3-D crystal lattice [See ESI, Fig. S1a].

Table 1. Solid-state X-ray crystallography bond parameters ${ }^{\mathrm{a}}$ for complexes $(\mathbf{1})_{2} \cdot \mathrm{CuBr}_{2}-(\mathbf{7})_{2} \cdot \mathrm{CuBr}_{2}$.

\begin{tabular}{|c|c|c|c|c|c|c|c|c|}
\hline Complex & Motif & $d(\mathrm{X} 2 \cdots \mathrm{Br}), \mathrm{A}$ & $\angle \mathrm{C} 2-\mathrm{X} 2 \cdots \mathrm{Br}\left({ }^{\circ}\right)$ & $\mathbf{R}_{\mathbf{X B}}{ }^{b}$ & Motif & $d(\mathrm{X} 5 \cdots \mathrm{Br}), \AA$ & $\angle \mathrm{C} 5-\mathrm{X} 5 \cdots \mathrm{Br}\left({ }^{\circ}\right)$ & $\mathbf{R}_{\mathbf{X B}}{ }^{\mathrm{b}}$ \\
\hline (1) $)_{2} \cdot \mathrm{CuBr}_{2}$ & $\mathrm{C} 2-\mathrm{Cl} 2 \cdots \mathrm{Br}-\mathrm{Cu}$ & $3.70^{\mathrm{c}}$ & $159.2^{c}$ & $1.03^{c}$ & $\mathrm{C} 5-\mathrm{Cl} 5 \cdots \mathrm{Br}-\mathrm{Cu}$ & $3.546[3.661]$ & $170.6[162.2]$ & $0.99[1.02]$ \\
\hline$(2)_{2} \cdot \mathrm{CuBr}_{2}$ & $\mathrm{C} 2-\mathrm{Cl} 2 \cdots \mathrm{Br}-\mathrm{Cu}$ & $3.727^{c}$ & $159.3^{c}$ & $1.04^{c}$ & $\mathrm{C} 5-\mathrm{Br} 5 \cdots \mathrm{Br}-\mathrm{Cu}$ & 3.489 [3.624] & $173.1[161.1]$ & $0.94[0.98]$ \\
\hline$(3)_{2} \cdot \mathrm{CuBr}_{2}$ & $\mathrm{C} 2-\mathrm{Cl} 2 \cdots \mathrm{Br}-\mathrm{Cu}$ & $3.603^{c}$ & $161.0^{c}$ & $1.00^{c}$ & $\mathrm{C} 5-15 \cdots \mathrm{Br}-\mathrm{Cu}$ & $3.478[3.506]^{\mathrm{d}}$ & $174.2[170.9]^{\mathrm{d}}$ & $0.91[0.92]^{\mathrm{d}}$ \\
\hline$(4)_{2} \cdot \mathrm{CuBr}_{2}$ & $\mathrm{C} 2-\mathrm{Br} 2 \cdots \mathrm{Br}-\mathrm{Cu}$ & 3.492 [3.460] & $163.7[163.4]$ & $0.94[0.94]$ & $\mathrm{C} 5-\mathrm{F} 5 \cdots \mathrm{Br}-\mathrm{Cu}$ & $3.741^{\mathrm{e}}$ & $161.3^{\mathrm{e}}$ & $1.13^{\mathrm{e}}$ \\
\hline$(5)_{2} \cdot \mathrm{CuBr}_{2}$ & $\mathrm{C} 2-\mathrm{Br} 2 \cdots \mathrm{Br}-\mathrm{Cu}$ & $3.544[3.460]$ & $163.9[163.4]$ & $0.96[0.94]$ & $\mathrm{C} 5-\mathrm{Cl} 5 \cdots \mathrm{Br}-\mathrm{Cu}$ & $3.550[3.661]$ & $171.2[162.2]$ & 0.99 [1.02] \\
\hline$(6)_{2} \cdot \mathrm{CuBr}_{2}$ & $\mathrm{C} 2-\mathrm{Br} 2 \cdots \mathrm{Br}-\mathrm{Cu}$ & $3.565[3.460]$ & $165.0[163.4]$ & $0.96[0.94]$ & $\mathrm{C} 5-\mathrm{Br} 5 \cdots \mathrm{Br}-\mathrm{Cu}$ & $3.507[3.624]$ & $172.6[161.1]$ & $0.95[0.98]$ \\
\hline$(7)_{2} \cdot \mathrm{CuBr}_{2}$ & $\mathrm{C} 2-\mathrm{Br} 2 \cdots \mathrm{Br}-\mathrm{Cu}$ & 3.531 [3.460] & $168.0[163.4]$ & $0.95[0.94]$ & $\mathrm{C} 5-15 \cdots \mathrm{Br}-\mathrm{Cu}$ & $3.523[3.506]$ & $173.2[170.9]$ & $0.92[0.92]$ \\
\hline
\end{tabular}

${ }^{a}$ The values in parentheses are C2- and C3-halogen based XB bond parameters in mono-substituted halopyridine-CuBr2 complexes extracted from CSD database ${ }^{13}$; ${ }^{\mathrm{b}} \mathrm{The}$ normalized interaction ratio, $R_{x B}$, is defined as $\left(R \times B=d \times B / X_{v d w}+B v d w\right),{ }^{14}$ where $d \times B[\AA]$ is the distance between the donor atom $(X)$ and the acceptor atoms $(B)$ and divided by the sum of vdW radii $[\AA]$ of $X$ and $\mathrm{B}$. The van der Waals radii determined by Bondi were used to calculate $\mathrm{R} \times \mathrm{B}$ values. ${ }^{15}$; ${ }^{\mathrm{C}}$ The values are only for reference purpose and no $\mathrm{C} 2-\mathrm{Cl} 2 \cdots \mathrm{Br}-\mathrm{Cu} \mathrm{XBs}$ were observed; ${ }^{\mathrm{d}} \mathrm{Part}$ of

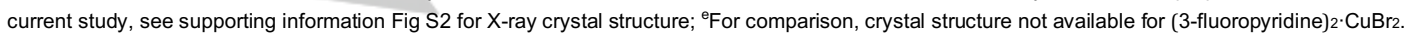


In $(3)_{2} \cdot \mathrm{CuBr}_{2}$, the distorted $\mathrm{Cu}(\mathrm{II})$ geometry and the relative synpositions of bromides bound to $\mathrm{Cu}(\mathrm{II})$ ion and $\mathrm{I} 5$ of 3 favour 1-D polymeric zig-zag structure [Fig. 3c] through $\mathrm{C} 5-15 \cdots \mathrm{Br}-\mathrm{Cu}$ halogen bonds $\left[R_{X B}=0.91\right]$. A closer inspection of crystal packing in $\left.{ }_{(3)}\right)_{2} \cdot \mathrm{CuBr}_{2}$, reveals also weak $\mathrm{C} 2-\mathrm{Cl} 2 \cdots \mathrm{Br}-\mathrm{Cu}$ contacts between adjacent 1-D chains [See ESI, Fig. S1b]. Thus, the order of $\mathrm{XB}$ strength increases in the order: $(1)_{2} \cdot \mathrm{CuBr}_{2}<(2)_{2} \cdot \mathrm{CuBr}_{2}<$ (3) $)_{2} \cdot \mathrm{CuBr}_{2}$ according to the electrophilic character of the halogens $^{[6 \mathrm{c}]}$ i.e., $\mathrm{Cl} 5<\mathrm{Br} 5<15$ [Fig. 2e-g].
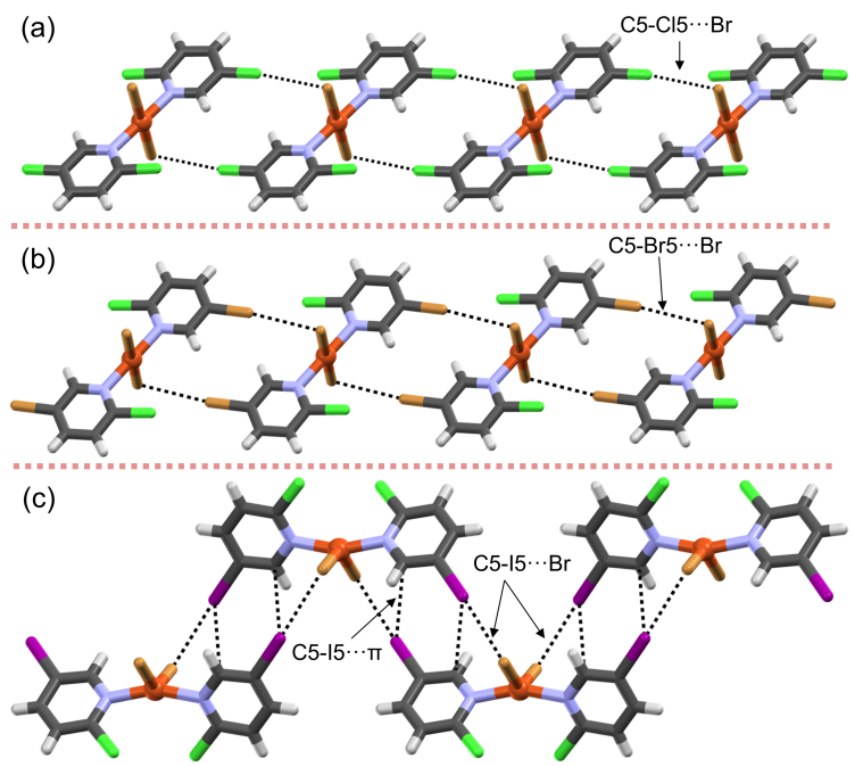

Figure 3. Section of crystal packing to display the 1-D halogen bonded polymeric structures in (a) (1) $)_{2} \cdot \mathrm{CuBr}_{2}$, (b) $(2)_{2} \cdot \mathrm{CuBr}_{2}$ and (c) $(3)_{2} \cdot \mathrm{CuBr}_{2}$. The halogen bonds are shown in black dotted lines.

The $2 \mathrm{BrPy}$ in the previously published $(2-\mathrm{BrPy})_{2} \cdot \mathrm{CuCl}_{2}$ complex can be regarded as chelating rather than mono-dentate ligand, and $\mathrm{Cu}(\mathrm{II})$ ion as octahedral rather than square planar. ${ }^{[16]}$ The report ${ }^{[16]}$ reasoned that, the unusually short $\mathrm{C} 2-\mathrm{Br} 2 \cdots \mathrm{Cu}$ distance between the ortho-bromide and square planar $\mathrm{Cu}(\mathrm{II})$ ion results in a pseudo-octahedral $\mathrm{N}_{2} \mathrm{Cl}_{2} \mathrm{Br}_{2}$ coordination sphere. In fact, the role of $\mathrm{C} 2-\mathrm{X} \cdots \mathrm{Cu}$ type interactions were overlooked in solid-state chemistry, although they are important to stabilize both metals and coordination polymers. The X-ray crystal structures of $(4)_{2} \cdot \mathrm{CuBr}_{2},(5)_{2} \cdot \mathrm{CuBr}_{2},(6)_{2} \cdot \mathrm{CuBr}_{2}$ and $(7)_{2} \cdot \mathrm{CuBr}_{2}$ all contain square planar $\mathrm{Cu}(\mathrm{II})$ ions, and exhibit $\mathrm{C} 2-\mathrm{Br} 2 \cdots \mathrm{Cu}$ interactions as shown in Fig. 4. The increase in size of the $\mathrm{X} 2, \mathrm{Cl}$ to $\mathrm{Br}$, increases the possibility to $\mathrm{X} 2 \cdots \mathrm{Cu}$ interactions, and makes it a significant synthon of interest. Such systems have been studied using computational methods and X-ray crystal structures by Awwadi et al. ${ }^{[16]}$ The electrostatic negative potential around $\mathrm{X} 2$ interacts with the electrophile i.e., $\mathrm{Cu}(\mathrm{II})$ ion. Halogens $\mathrm{F}, \mathrm{Cl}, \mathrm{Br}$ and I positioned para to the $\mathrm{Br} 2$ have an influence to the $\mathrm{C} 2-\mathrm{Br} 2 \cdots \mathrm{Cu}$ interaction, as shown in Fig. 4. Our results show that the higher the electronegativity of the $\mathrm{X} 5$ is, the shorter the shorter the $\mathrm{C} 2$ $\mathrm{Br} 2 \cdots \mathrm{Cu}$ interaction distances. The $\mathrm{C} 2-\mathrm{Br} 2 \cdots \mathrm{Cu}$ contacts of $3.074 \AA$ in $(4)_{2} \cdot \mathrm{CuBr}_{2}$ is similar to distances observed in $(2 \mathrm{BrPy})_{2} \cdot \mathrm{CuBr}_{2}[3.071 \AA] \cdot{ }^{[11 b]}$
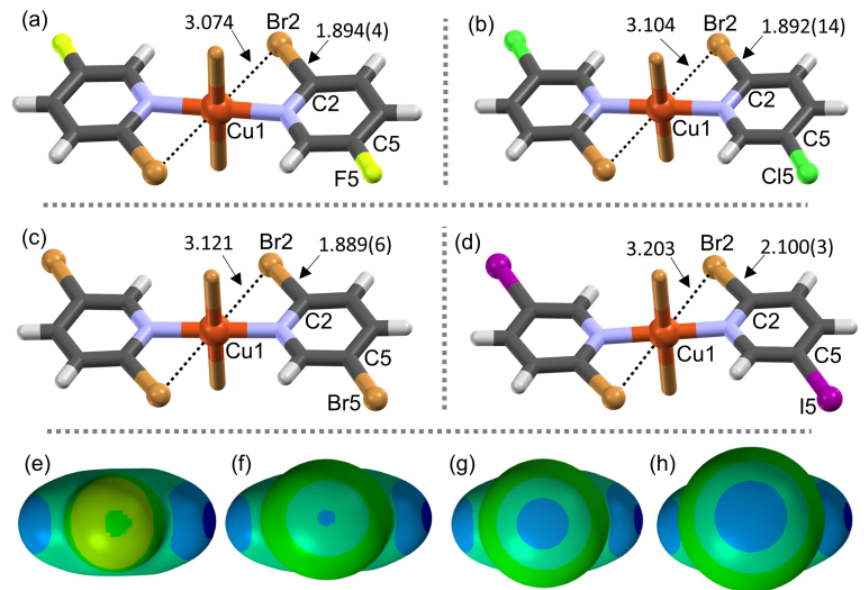

Figure 4. X-ray Crystal structures of (a) (4) $)_{2} \cdot \mathrm{CuBr}_{2}$, (b) (5) $)_{2} \cdot \mathrm{CuBr}_{2}$, (c) (6) ${ }_{2} \cdot \mathrm{CuBr}_{2}$ and (d) $(7)_{2} \cdot \mathrm{CuBr}_{2}$ to display pseudo-octahedral $\mathrm{Cu}(\mathrm{II})$ ion with $\mathrm{N} 2 \mathrm{Br} 4$ coordination sphere. The electrostatic potential surfaces of the X5 of the free ligands are shown in (e) for $4(F)$, (f) for $5(\mathrm{Cl}),(\mathrm{g})$ for $\mathbf{6}(\mathrm{Br})$ and $(\mathrm{h})$ for $7(\mathrm{I})$.

Complexes $(4)_{2} \cdot \mathrm{CuBr}_{2},(5)_{2} \cdot \mathrm{CuBr}_{2}$ and $(6)_{2} \cdot \mathrm{CuBr}_{2}$, crystallize in the triclinic space group $P-1$, are isomorphous and isostructural, while $(7)_{2} \cdot \mathrm{CuBr}_{2}$ crystallizes in monoclinic space group $P 2_{1} / n$ and packs with a herringbone pattern. The structure of $(6)_{2} \cdot \mathrm{CuBr}_{2}$ is similar to previously reported (CCDC code XIBSAE). ${ }^{[17]}$ The formation of $1-\mathrm{D}$ polymers in $(\mathbf{4})_{2} /(\mathbf{5})_{2} /(\mathbf{6})_{2} /(\mathbf{7})_{2} \cdot \mathrm{CuBr}_{2}$ is due to interactions between the $\mathrm{Br} 2$ and $\mathrm{Br}-\mathrm{Cu}$ instead of $\mathrm{X} 5$ as observed in $(1)_{2} /(2)_{2} /(3)_{2} \cdot \mathrm{CuBr}_{2}$ structures. The $\mathrm{C} 2-\mathrm{Br} 2 \cdots \mathrm{Br}-\mathrm{Cu}$ $\mathrm{XBs}$ in $(\mathbf{4})_{2} /(\mathbf{5})_{2} /(\mathbf{6})_{2} /(\mathbf{7})_{2} \cdot \mathrm{CuBr}_{2}$ have RXB's $0.94,0.96,0.96$ and 0.95 , respectively. The $\mathrm{C} 5-\mathrm{X} 5 \cdots \mathrm{Br}-\mathrm{Cu}(\mathrm{X}=\mathrm{Cl}, \mathrm{Br}$ and $\mathrm{I})$ halogen bonded 1-D polymers in $(5)_{2} /(\mathbf{6})_{2} /(7)_{2} \cdot \mathrm{CuBr}_{2}$ are interconnected with secondary weak $\mathrm{XBs}$ between the $\mathrm{Br} 2$ and the adjacent polymer $\mathrm{Br}-\mathrm{Cu}$, extending the polymers into 2-D network as shown in Fig. $5 \mathrm{a}-\mathrm{C}$. The $\mathrm{X} 5 \cdots \mathrm{Br}$ halogen bond distances with RXB's $0.99,0.95$ and 0.92 are longer than the corresponding values observed in $(1)_{2} /(2)_{2} /(3)_{2} \cdot \mathrm{CuBr}_{2}$ complexes. The $\mathrm{C}_{5}$ $\mathrm{F} 5 \cdots \mathrm{Br}-\mathrm{Cu}$ distances in $(4)_{2} \cdot \mathrm{CuBr}_{2}$ are above the sum of the vdW radii $[3.32 \AA]$, and cannot be regarded as halogen bonds. However, their relative positioning in the crystal lattice is caused due to favourable electrostatic interactions. To rationalize $C_{-}$ $\mathrm{X} \cdots \mathrm{Br}-\mathrm{Cu}$ contacts, X-ray crystal structure coordinates of 1:2 metal-ligand complexes were used to calculate electrostatic potential surfaces for the X2- and X5 substituents [see ESI]. ${ }^{[18]}$ The $X 2$ and $X 5$ substituents, notably chlorides, in modelled free ligands [Fig. 2 and 4] show more pronounced positive potential compared to $\mathrm{Cu}$ (II) complexes [see ESI, Fig. S3-S9].

Non-covalent electrostatic interactions can either be strong or act at long range, and are overlooked due to difficulty in visualizing clear surface potentials. The isostructural packing in $(4)_{2} \cdot \mathrm{CuBr}_{2}$, $(5)_{2} \cdot \mathrm{CuBr}_{2}$ and $(6)_{2} \cdot \mathrm{CuBr}_{2}$, can be used to view ligand alignments for short and long range contacts. In $(4)_{2} \cdot \mathrm{CuBr}_{2}$, the formally negatively charged bromide of $\mathrm{Cu}-\mathrm{Br}$ and aromatic $\mathrm{C} 5$-carbon of C5-F5 exhibit $\mathrm{Cu}-\mathrm{Br} \cdots \mathrm{C}(\pi)$ contacts with $\mathrm{R}_{\mathrm{XB}}=0.98[3.485 \AA$ A $]$. The halogen $\cdots C(\pi)$ interaction in $(4)_{2} \cdot \mathrm{CuBr}_{2}$, and similarly short contacts observed in other 

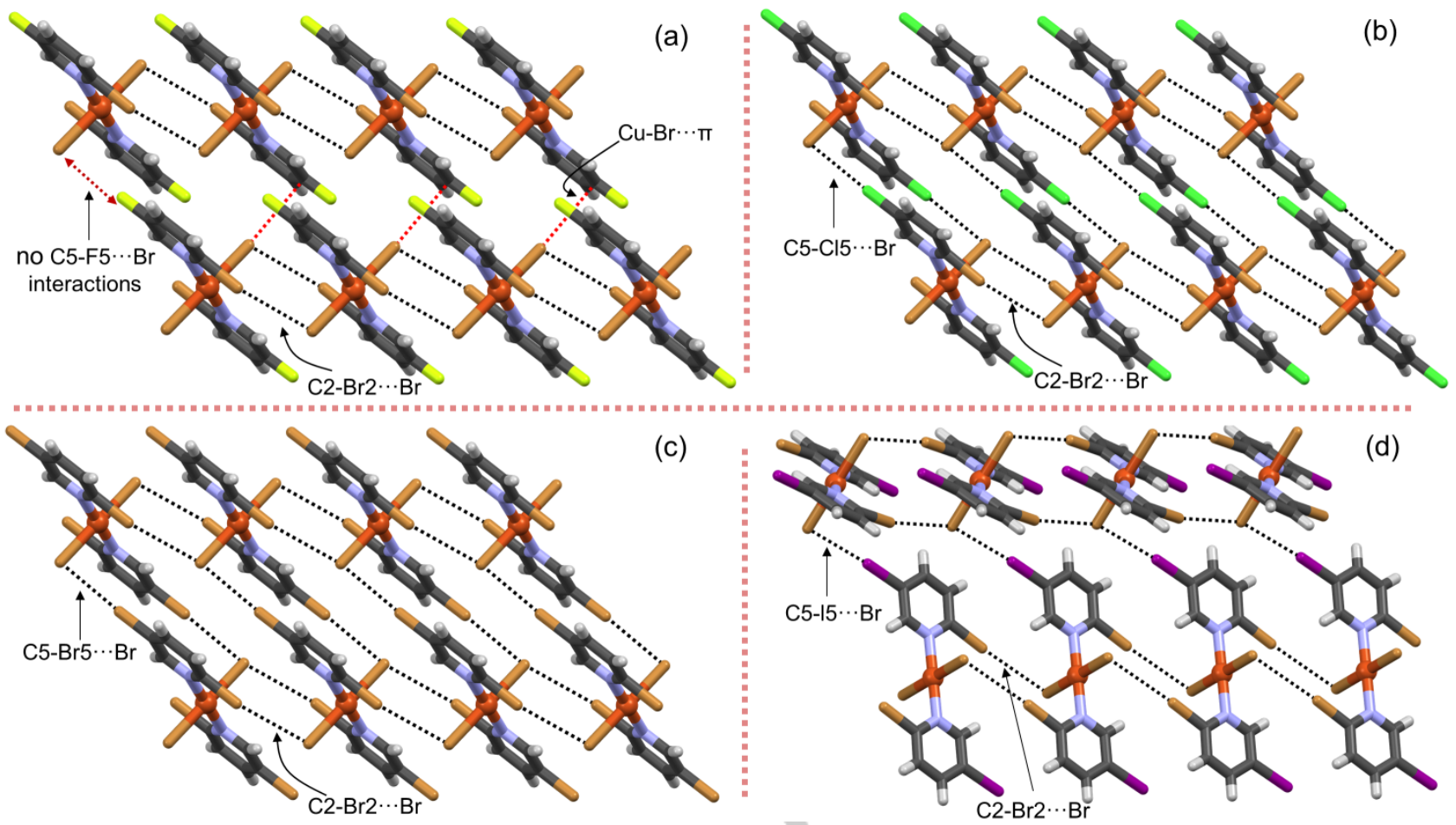

The modulation of the $\mathrm{C}-\mathrm{X} \cdots \mathrm{Br}-\mathrm{Cu}$ halogen bonds and $\mathrm{C}-\mathrm{X} \cdot \mathrm{Cu}$ interactions using a series of 2,5-dihalopyridines have been demonstrated in 2,5-dihalopyridine-copper(II) bromide complexes. Compared to previously published mono-substituted halopyridines, the di-substituted halopyridines have been proven to act as better synthons to understanding the electronic donoracceptor properties in solid-state. The discrete 1:2 metal-ligand

complexes form 1-D polymer chains through halogen bonds between the halogen X2 or X5 substituent (donor) and copperbound bromide anion (acceptor). In (2-chloro-5halopyridine $)_{2} \cdot \mathrm{CuBr}_{2}$ complexes, only $\mathrm{X} 5$ forms halogen bonds. However, in (2-bromo-5-halopyridine) ${ }_{2} \cdot \mathrm{CuBr}_{2}$ both $\mathrm{X} 2$ and $\mathrm{X} 5$ substituents form $\mathrm{C}-\mathrm{X} \cdots \mathrm{Br}-\mathrm{Cu}$ halogen bonds. The more electronegative $\mathrm{F} 5$ in (2-bromo-5-fluoropyridine) ${ }_{2} \cdot \mathrm{CuBr}_{2}$ is $\mathrm{XB}$ passive but polarizes the $\mathrm{Br} 2$ to form $\mathrm{Br} 2 \cdots \mathrm{Br}-\mathrm{Cu}$ halogen bonds. The $\mathrm{C} 5-\mathrm{X} 5 \cdots \mathrm{Br}-\mathrm{Cu}$ halogen bond angles for the $(2,5-$ dihalopyridine $)_{2} \cdot \mathrm{CuBr}_{2}$ complexes are closer to $180^{\circ}$ when compared to the previously reported $\mathrm{C} 3-\mathrm{X} 3 \cdots \mathrm{Br}-\mathrm{Cu}$ in (3halopyridine $)_{2} \cdot \mathrm{CuBr}_{2}$ complexes. The $\mathrm{C} 2-\mathrm{X} 2 \cdots \mathrm{Br}-\mathrm{Cu}$ and $\mathrm{C} 5-$ $\mathrm{X} 5 \cdots \mathrm{Br}-\mathrm{Cu}$ halogen bonds are of similar strength in (2-bromo-5halopyridine $)_{2} \cdot \mathrm{CuBr}_{2}$ complexes due to competition of both $\mathrm{X} 2$ and $\mathrm{X} 5$ for halogen bonds. All complexes exhibit pseudooctahedral $\mathrm{C} 2-\mathrm{X} 2 \cdots \mathrm{Cu}$ contacts, with stronger interactions for bromide than for chloride.

\section{Experimental Section}

General information: All solvents used for crystal growth were reagent grade and are used as received without further purification. The ligands, 2,5-dichloropyridine (1), 5-bromo-2-chloropyridine (2), 2-chloro-5iodopyridine (3), 2-bromo-5-fluoropyridine (4), 2-bromo-5-chloropyridine (5), 2,5-dibromopyridine (6), 2-bromo-5-iodopyridine (7) and 3iodopyridine (3IPy) were purchased from $\mathrm{TCl}$ Chemicals Europe, and copper(II) bromide from Sigma Aldrich. Infrared spectra were recorded using Bruker Tensor 27 FTIR spectrometer in attenuated total reflection (ATR) mode. See Supporting Information Figs. S11 - S18 for IR spectra. 
General crystallization procedure: $\mathrm{To}$ a solution of $\mathrm{CuBr}_{2}(0.067 \mathrm{mmol})$ in acetonitrile $(1.0 \mathrm{ml})$, was added respective 2,5-dihalopyridine $(0.134$ $\mathrm{mmol})$ dissolved in acetonitrile $(0.5 \mathrm{ml})$ at room temperature. In case of precipitation, the samples were sonicated to clear solutions. The solutions were left in dark at room temperature, and subjected to slow evaporation to give single crystals suitable for $\mathrm{X}$-ray diffraction analysis.

(1)2. $\mathrm{CuBr}_{2}: \mathrm{IR} V_{\max } \mathrm{Cm}^{-1}: 3070,2918,2552,1678,1581,1452,1417,1323$, $1286,1180,1100,913,803,702,664,542,430$.

(2) $2 \cdot \mathrm{CuBr}_{2}: \mathrm{IR} v_{\max } \mathrm{Cm}^{-1}: 3088,1549,1450,1410,1357,1233,1109,1096$, 1042, 912, 827, 717, 661, 516, 498, 438.

(3) $2 \cdot \mathrm{CuBr}_{2}: \mathrm{IR} v_{\max } \mathrm{Cm}^{-1}: 3082,1558,1443,1346,1130,1021,906,817$, $715,643,493,483,414$.

(4) $)_{2} \cdot \mathrm{CuBr}_{2}: \mathrm{IR} V_{\max } \mathrm{Cm}^{-1}: 3088,2388,1578,1456,1373,1267,1229,1097$, $1031,832,711,601,528,439,430$.

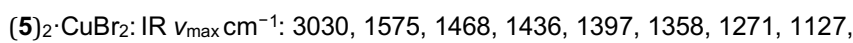
1109, 1086, 1003, 913, 829, 754, 716, 624, 484.

(6) ${ }_{2} \cdot \mathrm{CuBr}_{2}: \mathrm{IR} v_{\max } \mathrm{Cm}^{-1}: 3086,1569,1466,1401,1354,1278,1231,1124$, $1101,1085,1041,907,827,754,713,659,495,435$.

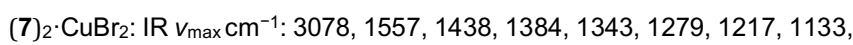
1095, 1073, 1040, 1017, 904, 815, 708, 659, 640, 477, 409.

$(3 \mid \mathrm{Py})_{2} \cdot \mathrm{CuBr}_{2}: \mathrm{IR} v_{\max } \mathrm{Cm}^{-1}: 3052,1584,1460,1417,1407,1324,1223$, 1193, 1120, 1042, 1030, 915, 790, 685, 648, 527, 450, 409.

Crystal structure determination: The X-ray single crystal data and experimental details for data collections are given in Supporting Information Table S1 and S2. Single-crystal X-ray data for $(1)_{2} \cdot \mathrm{CuBr}_{2}$, (2) $)_{2} \cdot \mathrm{CuBr}_{2},(\mathbf{3})_{2} \cdot \mathrm{CuBr}_{2},(\mathbf{4})_{2} \cdot \mathrm{CuBr}_{2},(\mathbf{5})_{2} \cdot \mathrm{CuBr}_{2},(\mathbf{6})_{2} \cdot \mathrm{CuBr}_{2}$ and $(\mathbf{7})_{2} \cdot \mathrm{CuBr}_{2}$, were measured on a Bruker-Nonius Kappa CCD diffractometer equipped with an APEX-II CCD detector using graphite-monochromated Mo-Ka $(\lambda=$ $0.71073 \AA$ ) radiation. The data for $(3 \mathrm{IPy})_{2} \cdot \mathrm{CuBr}_{2}$ was measured at 120.0 $\mathrm{K}$ using a Rigaku SuperNova dual-source Oxford diffractometer equipped with an Atlas detector using mirror-monochromated $\mathrm{Cu}-\mathrm{Ka}(\lambda=1.54184 \AA)$ radiation. The data collection and reduction for $(3 / \mathrm{Py})_{2} \cdot \mathrm{CuBr}_{2}$ were performed using the program CrysAlisPro. ${ }^{20}$ For the data obtained from Bruker Nonius Kappa diffractometer were performed using the program COLLECT $^{21}$ and HKL DENZO AND SCALEPACK. ${ }^{22}$ The gaussian face index absorption correction method ${ }^{20}$ was used for $(3 \mathrm{Pyy})_{2} \cdot \mathrm{CuBr}_{2}$. The intensities for data collected using Bruker Nonius Kappa diffractometer were corrected for absorption using SADABS ${ }^{23}$ with multi-scan absorption correction type method. All structures were solved with direct methods $(S H E L X S)^{24}$ and refined by full-matrix least squares on $F^{2}$ using the OLEX2 software ${ }^{25}$, which utilizes the SHELXL-2013 module. ${ }^{24}$

\section{Acknowledgements}

The authors gratefully acknowledge financial support from the Academy of Finland (RP: grant no. 298817) and the University of Jyväskylä.

Keywords: halogen bond $\cdot$ halopyridine $\cdot \operatorname{copper}(\mathrm{II})$ complexes • $\mathrm{X}$-ray crystallography $\cdot$ intermolecular interactions

[1] (a) G. A. Jeffrey, An Introduction to Hydrogen Bonding, Oxford University Press, New York and Oxford, 1997; (b) G. R. Desiraju, T. Steiner, The Weak Hydrogen Bond: In Structural Chemistry and Biology, International union of Crystallography, Monographs on Crystallography, Oxford University Press, Oxford and New York, 2001; (c) G. Gilli, P. Gilli, The
Nature of the Hydrogen Bond: Outline of a Comprehensive Hydrogen Bond Theory, OUP Oxford, New York, 2009; (d) I. Haiduc, F. T. Edelmann, Supramolecular Organometallic Chemistry, Wiley-VCH, Weinheim, 2008.

[2] (a) L. C. Gilday, S. W. Robinson, T. A. Barendt, M. J. Langton, B. R. Mullaney, P. D. Beer, Chem. Rev. 2015, 115, 7118-7195; (b) H. Wang, W. Wang, W. J. Jin, Chem. Rev. 2016, 116, 5072-5104. (c) G. Cavallo, P. Metrangolo, R. Milani, T. Pilati, A. Priimagi, G. Resnati, G. Terraneo, Chem. Rev. 2016, 116, 2478-2601;

[3] (a) A. M. Maharramov, K. T. Mahmudov, M. N. Kopylovich, A. J. L. Pombeiro, Non-Covalent Interactions in the Synthesis and Design of New Compounds, Wiley-VCH, 2016. (b) Troff, R. W.; Mäkelä, T.; Topic, F.; Valkonen, A.; Raatikainen, K.; Rissanen, K. Eur. J. Org. Chem. 2013, 2013, 1617-1637. 456. (c) Rissanen, K. CrystEngComm 2008, 10, 1107-1113. 457, (d) L. Brammer, Chem. Soc. Rev. 2004, 33, 476-489.

[4] (a) G. R. Desiraju, P. S. Ho, L. Ko, A. C. Legon, R. Marquardt, P. Metrangolo, P. Politzer, G. Resnati and K. Rissanen, Pure Appl. Chem. 2013, 85, 1711; (b) P. Metrangolo, G. Resnati, IUCrJ, 2014, 1, 5-7.

[5] (a) P. Metrangolo, Y. Carcenac, M. Lahtinen, T. Pilati, K. Rissanen, A. Vij and G. Resnati, Science, 2009, 323, 1461-1464; (b) A. Abate, M. Brischetto, G. Cavallo, M. Lahtinen, P. Metrangolo, T. Pilati, S. Radice, G. Resnati, K. Rissanen and G. Terraneo, Chem. Commun., 2010, 46, 27242726; (c) M. Müller, M. Albrecht, V. Gossen, T. Peters, A. Hoffmann, G. Raabe, A. Valkonen and K. Rissanen, Chem. Eur. J, 2010, 16, 1244612453.

[6] (a) M. H. Koláŕ, P. Hobza, Chem. Rev. 2016, 116, 5155-5187 (reference therein); (b) F. F. Awwadi, R. D. Willett, K. A. Peterson, B. Twamley, Chem. - A Eur. J. 2006, 12, 8952-8960 (reference therein); (c) K. Riley, J. Murray, J. Fanfrlík, J. Řezáč, R. Solá, M. Concha, F. Ramos, P. Politzer, J. Mol. Model. 2011, 17, 3309-3318; (d) P. Politzer, J. S. Murray, ChemPhysChem 2013, 14, 278-294; (e) P. Politzer, J. S. Murray, T. Clark, Phys. Chem. Chem. Phys. 2013, 15, 11178-11189; (f) P. Politzer, J. S. Murray, T. Clark, Phys. Chem. Chem. Phys. 2013, 15, 11178-11189; (g) T. Clark, P. Politzer, J. S. Murray, Wiley Interdiscip. Rev. Comput. Mol. Sci. 2015, 5, 169-177; (h) P. Politzer, K. E. Riley, F. A. Bulat, J. S. Murray, Comput. Theor. Chem. 2012, 998, 2-8.

[7] (a) R. L. Shook, A. S. Borovik, Inorg. Chem. 2010, 49, 3646-3660 (reference therein); (b) S. A. Cook, A. S. Borovik, Acc. Chem. Res. 2015, 48, 2407-2414

[8] (a) F. Zordan, L. Brammer, P. Sherwood, J. Am. Chem. Soc. 2005, 127, 5979-5989; (b) F. Zordan, L. Brammer, Cryst. Growth Des. 2006, 6, 13741379.

[9] (a) F. Zordan, S. L. Purver, H. Adams, L. Brammer, CrystEngComm 2005, 7, 350-354; (b) L. Brammer, G. Minguez Espallargas, H. Adams, CrystEngComm 2003, 5, 343-345; (c) G. Mínguez Espallargas, L. Brammer, P. Sherwood, Angew. Chemie Int. Ed. 2006, 45, 435-440.

[10] (a) M. T. Johnson, Z. Džolić, M. Cetina, O. F. Wendt, L. Öhrström, K. Rissanen, Cryst. Growth Des. 2012, 12, 362-368; (b) B. N. Ghosh, M. Lahtinen, E. Kalenius, P. Mal, K. Rissanen, Cryst. Growth Des. 2016, 16, 2527-2534.

[11] (a) F. Awwadi, R. D. Willett, B. Twamley, Cryst. Growth Des. 2011, 11, 5316-5323; (b) F. Awwadi, R. D. Willett, S. F. Haddad, B. Twamley, Cryst. Growth Des. 2006, 6, 1833-1838.

[12] L. Yang, D. R. Powell, R. P. Houser, Dalton Trans. 2007, 955-964

[13] (a) The Cambridge Structural database 2018 [updated December 2017], ConQuest version 1.19; (b) I. J. Bruno, J. C. Cole, P. R. Edgington, M. Kessler, C. F. Macrae, P. McCabe, J. Pearson, R. Taylor, Acta Crystallogr. Sect. B 2002, 58, 389-397.

[14] R. Puttreddy, O. Jurček, S. Bhowmik, T. Mäkelä, K. Rissanen, Chem. Commun. 2016, 52, 2338-2341.

[15] A. Bondi, J. Phys. Chem. 1964, 68, 441-451

[16]F. F. Awwadi, R. D. Willett, B. Twamley, M. M. Turnbull, C. P. Landee, Cryst. Growth Des. 2015, 15, 3746-3754.

[17] F. F. Awwadi, S. F. Haddad, M. M. Turnbull, C. P. Landee, R. D. Willett, CrystEngComm 2013, 15, 3111-3118.

[18] Spartan'16 (version 2.0.8), Wavefunction, Inc., Irvine, USA.. 


\section{FULL PAPER}

[19] (a) M. A. Spackman, D. Jayatilaka, CrystEngComm 2009, 11, 19-32; (b) J. J. McKinnon, M. A. Spackman, A. S. Mitchell, Acta Crystallogr. Sect. B 2004, 60, 627-668; (c) M. A. Spackman, J. J. McKinnon, D. Jayatilaka, CrystEngComm 2008, 10, 377-388.

[20] Rigaku Oxford Diffraction 2017, CrysAlisPro Version 1.171.38.43.

[21] Bruker AXS BV, Madison, WI, USA; 1997-2004.

[22] Z. Otwinowski, W. Minor, Methods Enzymol. 1997, 276, 307-326.

[23] R. H. Blessing, J. Appl. Cryst. 1997, 30, 421-426.

[24] (a) G. M. Sheldrick, Acta Cryst. 2008, A64, 112-122; (b) G. M. Sheldrick, Acta Cryst. 2015, A71, 3-8.

[25] O. V. Dolomanov, L. J. Bourhis, R. J. Gildea, J. A. K. Howard, H. J. Puschmann, J. Appl. Cryst. 2009, 42, 339-341.

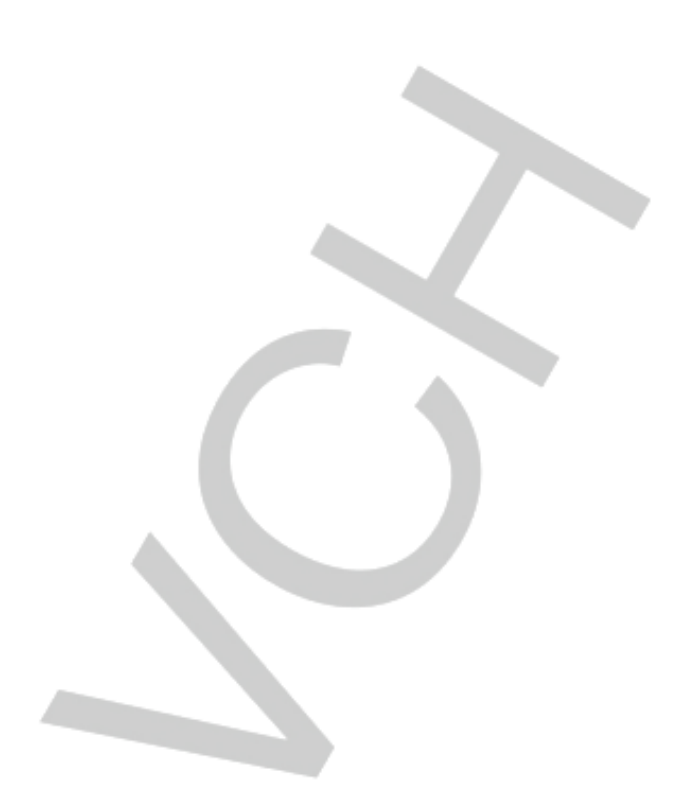


WILEY-VCH

FULL PAPER

\section{Entry for the Table of Contents}

Layout 2:

\section{FULL PAPER}

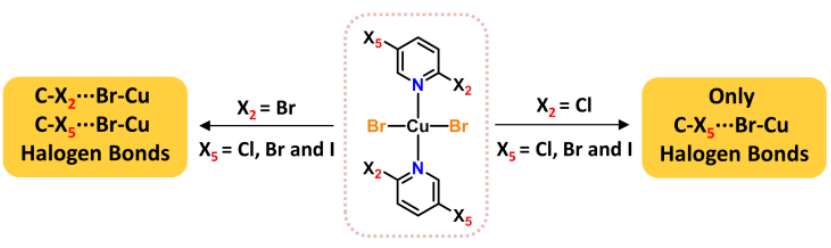

\section{Halogen Bonding \\ Rakesh Puttreddy*, Carolina von Essen and Kari Rissanen* \\ Page No. - Page No. \\ Halogen Bonds in Square Planar 2,5- Dihalopyridine-Copper(II) Bromide Complexes}

Table of contents text: 2,5-Dihalopyridine-copper(II) bromide complexes were investigated aiming to understand the mutual polarization of $\mathrm{X} 2$ on $\mathrm{X} 5$ and vice versa, and their effect on $\mathrm{C}-\mathrm{X} 2 / \mathrm{X} 5 \cdots \mathrm{Br}-\mathrm{Cu}$ halogen bond distances in solid-state $\mathrm{X}$-ray crystal structures. In this approach, the change in $\mathrm{C}-\mathrm{X} 2 / \mathrm{X} 5 \cdots \mathrm{Br}-\mathrm{Cu}$ halogen bond distances due to $\mathrm{X} 2-/ \mathrm{X} 5$-substituent effects are evaluated by comparing with $\mathrm{C}-\mathrm{X} 2 / \mathrm{X} 3 \cdots \mathrm{Br}-\mathrm{Cu}$ halogen bonds in $(2-\mathrm{X} \text {-pyridine })_{2} \cdot \mathrm{CuBr}_{2}(\mathrm{X}=\mathrm{Cl}$ and $\mathrm{Br})$ and $(3-\mathrm{X}-\mathrm{pyridine})_{2} \cdot \mathrm{CuBr}_{2}(\mathrm{X}=\mathrm{Cl}, \mathrm{Br}$ and I) complexes, respectively. Our results reveal, in (2-chloro-5-X-pyridine) $)_{2} \cdot \mathrm{CuBr}_{2}(\mathrm{X}=\mathrm{Cl}, \mathrm{Br}$ and I), only the $\mathrm{X} 5$, and in (2-bromo-5-Xpyridine $)_{2} \cdot \mathrm{CuBr}_{2}(\mathrm{X}=\mathrm{Cl}, \mathrm{Br}$ and $\mathrm{I})$ both, $\mathrm{X} 2$ - and $\mathrm{X} 5$, form $\mathrm{C}-\mathrm{X} \cdots \mathrm{Br}-\mathrm{Cu}$ halogen bonds. Several other interesting results such as predominant square planar $\mathrm{Cu}(\mathrm{II})$ centers and unqiue $\mathrm{C}-\mathrm{X} 2 \cdots \mathrm{Cu}$ interactions are reported as a part of our structure-property study that utilizes $\mathrm{C}-\mathrm{X} \cdots \mathrm{Br}-\mathrm{Cu}$ halogen bonds. 